$\mathrm{T}$ HHIS ISSUE BRINGS TO AN END ANOTHER satisfying and progressive year in the evolution of Cardiology in the Young. Perhaps the only downside of the year has been the number of obituaries published, giving details of the contributions of several giants in our field who, sadly, died over the previous 12 months. It is with additional sadness that we must now report the recent death of Atsuyoshi Takao, for many years Director of Paediatric Cardiology at Tokyo Women's Medical College. Professor Takao supported the activities of the Journal from its inception, and was largely responsible, along with Hiromi Kurosawa, for the support we have received from all our colleagues in Japan as we have developed our pages. He was also responsible for organising the hugely successful "Takao Symposiums", which brought to prominence the huge advances made in understanding the development of the heart, and their significance to clinical paediatric cardiology. We intend to publish a more detailed obituary in one of our early Issues in 2007 , but we take this opportunity of expressing our own condolences, as Editors and publishers, to his many relatives, friends, and colleagues. As with all those who passed away during 2006, he will be sorely missed.

In the "From the Editors" section of our August Issue, ${ }^{1}$ we described the changes made in our Editorial Board. In this Issue, we carry the extensive list of those outside the Board who have helped us in the assessment of the manuscripts submitted for publication. To all of those listed, and to those who have helped us in previous years, we extend our heartfelt gratitude. Assessment of manuscripts is a difficult task, and we are well aware that those we ask to review the material submitted to our Journal receive multiple similar requests from other journals. All of the Editors sending out material for review expect to have the assessments returned in reasonable time, and with most journals, like our own, this is usually within three weeks of receipt of the manuscript. The greater majority of reviewers fulfils these requests in timely fashion, and it is only a minority that requires reminders. Without this sterling support, which of course receives no financial reward, we would be unable to maintain the high scientific standards we now require to substantiate publication in the pages of the Journal. We state again, therefore, our indebtedness to all our referees, be they within or without the Editorial Board.
Very shortly, early in 2007, authors and readers of Cardiology in the Young will benefit from the introduction of three distinct electronic developments. Firstly, we will be moving to Manuscript Central ${ }^{\mathrm{TM}}$, an exclusively online system for submission of manuscripts. This will make the process of submission both faster and easier, and allow authors to track for themselves the progress of their manuscripts, providing assurance of the hopefully swift passage of their manuscript through the process of review. We will be publishing precise details as soon as they become available. In the meantime, our Editorial Assistant, Felicity Gil, will continue to ensure, with her legendary efficiency, that submitted manuscripts are dealt with in appropriate fashion. The electronic system has a hard act to follow!

The second electronic development is the move to incremental publishing. Within six weeks of acceptance of a manuscript for publication, and following the current procedures of copyediting, typesetting, and proofing, the proof approved by the author will be published on the homepage of the Journal within a section entitled "Forthcoming Articles". Each accepted paper will be assigned a digital object identifier, a unique code which then allows immediate citation of the paper. The paper, when about to be published within the pages of the Journal itself, will then be moved from this section, and will be listed under the appropriate Table of Contents for the Issue in which it is scheduled to appear. Approximately two weeks later, the paper version of the specific Issue will be printed, and distributed to subscribers. This development will provide authors of accepted submissions with the guarantee of fast publication, and will let subscribers read the latest material online with the briefest delay.

The third development reflects the fact that, over the past months, our publishers, Cambridge University Press, have confirmed their own commitment to the process of Open Access. Cardiology in the Young has been chosen as one of the flagship journals to pilot this electronic initiative. Through the Cambridge Open Option, our authors will now have the possibility of making their articles freely available to everyone, immediately on publication. On acceptance of a manuscript for publication, the corresponding author will be sent full details of how to take up this opportunity. This new service reflects the commitment of the Press to further the dissemination 
of published academic information. Users will have access to the full article, without restriction, and may download a copy in portable document format for their own personal, non-commercial, use. The Cambridge Open Option will test the viability of Open Access publishing as a model that is sustainable for everyone in the long term. Authors publishing in Cardiology in the Young, who choose to pay the sum of $£ 1500$, or $\$ 2700$, to make their articles freely available will continue to receive the benefits of publishing that they already experience. The same high standards of publishing will be unchanged. Cambridge will be assessing carefully the extent of uptake of this offer.

We finish our final comments for 2006 by endorsing the announcement of András Szatmári and Eero Jokinen concerning the success of the collaboration with the Association for European Paediatric Cardiology. As András and Eero state in their own newsletter (see page 610), the influx of new members to the Association means that over 800 interested persons are now eligible to receive the Journal as part of their annual subscription. All those not receiving the Journal have either not yet paid their dues, or else have supplied an incorrect address to the website

\section{Reviewers 2005-2006}

Analisa Angelini, Padova, Italy

Andrew Atz, Charleston, SC, United States of America

Kalimuddin Aziz, Karachi, Pakistan

Felix Berger, Berlin, Germany

Shuomo Bhattacharya, Oxford, United Kingdom

Ross Breckenridge, London, United Kingdom

Reiner Buchhorn, Bad Mergentheim, Germany

Michael Burch, London, United Kingdom

Enrico Chiappa, Torino, Italy

Louise Coats, London, United Kingdom

Gordon Cohen, Seattle, WA, United States of America Meryl Cohen, Philadelpha, PA, United States of America Andrew Cook, London, United Kingdom

Shay Cullen, London, United Kingdom

Eduardo Da Cruz, Geneva, Switzerland

Luciano Daliento, Padova, Italy

Otto Daniëls, Nijmegen, The Netherlands

Piers Daubeney, London, United Kingdom

Joseph DeGiovanni, Birmingham, United Kingdom

David Dickinson, Leeds, United Kingdom

Perry Elliott, London, United Kingdom

Benedicte Eyskens, Lewven, Belgium

Matthew Fenton, London, United Kingdom

Rodney Franklin, London, United Kingdom

Helena Gardiner, London, United Kingdom

Olivier Ghez, London, United Kingdom

John Gibbs, Leeds, United Kingdom of the Association - www.aepc.org. Our colleagues at Cambridge University Press responsible for distribution of the Journal have worked extensively with Eero over the past few months to make sure that all those eligible to receive the Journal are getting their Issues on time. The publishers have a dedicated Customer Services department, which is happy to resolve any queries relating to subscription. Contact details for the department can be found in the text at the end of the Table of Contents published in each Issue of the Journal, and also at the homepage of the Journal.

We end this year, therefore, by wishing all our readers a peaceful and fulfilling holiday season, and we look forward with confidence to an even better 2007.

Robert H. Anderson

G. William Henry

Dan Edwards

\section{Reference}

1. Anderson RH, Henry GW. From the Editors. Cardiol Young 2006; 16: 415-416.

Michael Godman, Riyadh, Saudi Arabia

Judith Goodship, Newcastle-upon-Tyne, United Kingdom

Julian Halcox, London, United Kingdom

Glennis Haworth, London, United Kingdom

Aparna Hoskote, London, United Kingdom

Marina Hughes, London, United Kingdom

Edgar Jaeggi, Toronto, Canada

Livia Kapusta, Nijmegen, The Netherlands

Sachin Khambadkone, London, United Kingdom

Laszlo Kiraly, Budapest, Hungary

François Lacour-Gayet, Denver, CO, United States of

America

Angela Lin, Boston, MA, United States of America

Martin Lowe, London, United Kingdom

Annette Majnemer, Montreal, Canada

Jan Marek, London, United Kingdom

Bruno Marino, Rome, Italy

Brian McCrindle, Toronto, Canada

Doff McElhinney, Boston, MA, United States of America

Karen McLeod, Glasgow, Scotland, United Kingdom

Hugh Montgomery, London, United Kingdom

Philip Moons, Lewven, Belgium

Cho Ng, London, United Kingdom

Elfriede Pahl, Chicago, IL, United States of America

Jonathan Parsons, Leeds, United Kingdom

Denis Pellerin, London, United Kingdom

Steffen Petersen, Oxford, United Kingdom

Shakeel Qureshi, London, United Kingdom 
Philip Rees, London, United Kingdom

Jonathan Rome, Philadelphia, PA, United States of

America

Mark Rosenthal, London, United Kingdom

Philip Saul, Charleston, SC, United States of America

Anna Seale, London, United Kingdom

Lara Shekerdemian, Melbourne, Australia

Michael Silberbach, Portland, OR, United States of

America

John Simpson, London, United Kingdom

Jane Somerville, London, United Kingdom

Henry Sondheimer, Denver, CO, United States of

America

Geoffrey Stevenson, Seattle, WA, United States of America Oliver Stumper, Birmingham, United Kingdom

Ian Sullivan, London, United Kingdom
Atsuko Suzuki, Tokyo, Japan

Andrew Taylor, London, United Kingdom

Christo Tchervenkov, Montreal, Canada

Judith Therrien, Montreal, Canada

Sara Thorne, Birmingham, United Kingdom

Victor Tsang, London, United Kingdom

Elizabeth Utens, Rotterdam, The Netherlands

Carin Van Doorn, London, United Kingdom

Joseph Vettukattil, Southampton, United Kingdom

Fiona Walker, London, United Kingdom

Colin Wallis, London, United Kingdom

Catherine Webb, Chicago, IL, United States of America

Neil Wilson, Oxford, United Kingdom

Maarten Witsenburg, Rotterdam, The Netherlands

Jo Wray, London, United Kingdom

Christopher Wren, Newcastle-upon-Tyne, United Kingdom 